\title{
Socioeconomic inequalities in injury mortality in small areas of 15 European cities
}

Mercè Gotsens ${ }^{\mathrm{a}, \mathrm{b}, \mathrm{c}}$, Marc Marí-Dell’Olmo ${ }^{\mathrm{a}, \mathrm{b}, \mathrm{c}}$, Katherine Pérez $^{\mathrm{b}, \mathrm{a}, \mathrm{c}}$, Laia Palència ${ }^{\mathrm{a}, \mathrm{b}, \mathrm{c}}$, Miguel-Angel Martinez-Beneito ${ }^{\mathrm{d}, \mathrm{a}}$, Maica Rodríguez-Sanz ${ }^{\mathrm{b}, \mathrm{ac}}$, Bo Burström $^{\mathrm{e}}$, Giuseppe Costa $^{\mathrm{f}}$, Patrick Deboosere ${ }^{\mathrm{g}}$, Felicitas Domínguez-Berjón ${ }^{\mathrm{h}}$, Dagmar Dzúrovái ${ }^{\mathrm{i}}$, Ana Gandarillas ${ }^{\mathrm{h}}$, Rasmus Hoffmann ${ }^{\mathrm{j}}$, Katalin Kovacs ${ }^{\mathrm{k}}$,

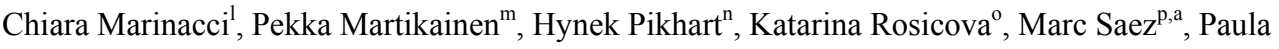
Santana $^{\mathrm{q}}$, Judith Riegelnig ${ }^{\mathrm{r}}$, Cornelia Schwierz ${ }^{\mathrm{r}}$, Lasse Tarkiainen $^{\mathrm{m}}$, Carme Borrell $^{\mathrm{b}, \mathrm{a}, \mathrm{s}, \mathrm{c}}$,

${ }^{a}$ CIBER Epidemiología y Salud Pública (CIBERESP), Spain

${ }^{\mathrm{b}}$ Agència de Salut Pública de Barcelona. Barcelona, Spain

${ }^{\mathrm{c}}$ Institut d'Investigació Biomèdica (IIB Sant Pau). Barcelona, Spain

${ }^{\mathrm{d}}$ Centro Superior de Investigación en Salud Pública, Valencia, Spain

${ }^{\mathrm{e}}$ Karolinska Institutet, Department of Public Health Sciences, Division of Social Medicine, Stockholm, Sweden

${ }^{\mathrm{f}}$ Department of Clinical and Biological Science, University of Turin, Turin, Italy

${ }^{g}$ Department of Social research, Vrije Universiteit Brussel, Brussels, Belgium

${ }^{\text {h }}$ Subdirección de Promoción de la Salud y Prevención. Consejería de Sanidad. Comunidad de Madrid, Spain

${ }^{i}$ Department of Social Geography and Regional Development, Faculty of Science, Charles University in Prague, Prague, Czech Republic

${ }^{\mathrm{j}}$ Department of Public Health, Erasmus Medical Center, Rotterdam, The Netherlands

${ }^{\mathrm{k}}$ Demographic Research Institute, Budapest, Hungary

${ }^{1}$ Epidemiology Unit, Local Health Unit TO3, Via, Turin, Italy

${ }^{\mathrm{m}}$ Department of Social Research, , University of Helsinki, Helsinki, Finland

${ }^{\mathrm{n}}$ Department of Epidemiology and Public Health, University College London, London, UK

${ }^{\circ}$ Graduate School Kosice Institute for Society and Health, Safarik University, Kosice, Slovakia

${ }^{\mathrm{p}}$ Research Group on Statistics, Econometrics and Health (GRECS), University of Girona, Girona, Spain

${ }^{\mathrm{q}}$ Centro de Estudos de Geografia e de Ordenamento do Territorio (CEGOT), Departamento de Geografia, Colégio de S. Jerónimo, Universidade de Coimbra, Coimbra, Portugal

${ }^{\mathrm{r}}$ Statistik Stadt Zürich, Zürich, Switzerland 
${ }^{\mathrm{s}}$ Universitat Pompeu Fabra, Barcelona, Spain

Address for correspondence:

Mercè Gotsens

Agència de Salut Pública de Barcelona

Plaça Lesseps 1

08023 Barcelona

Tel: 34-93-2384545

Fax: 34-93-2173197

e-mail: $\underline{\text { mgotsens@aspb.cat }}$

ABSTRACT

This study analysed socioeconomic inequalities in mortality due to injuries in small areas of 15 European cities, by sex, at the beginning of this century.

A cross-sectional ecological study with units of analysis being small areas within 15 European cities was conducted. Relative risks of injury mortality associated with the socioeconomic deprivation index were estimated using hierarchical Bayesian model.

The number of small areas varies from 17 in Bratislava to 2666 in Turin. The median population per small area varies by city (e.g. Turin had 274 inhabitants per area while Budapest had 76,970).

Socioeconomic inequalities in all injury mortality are observed in the majority of cities and are more pronounced in men. In the cities of northern and western Europe, socioeconomic inequalities in injury mortality are found for most types of injuries. These inequalities are not significant in the majority of cities in southern Europe among women and in the majority of central eastern European cities for both sexes.

The results confirm the existence of socioeconomic inequalities in injury related mortality, and reveal variations in their magnitude between different European cities.

Keywords: injuries, mortality, Europe, socioeconomic inequalities, urban areas, small areas 


\section{INTRODUCTION}

Injuries due to external causes, whether intentional or unintentional, are one of the leading causes of death worldwide. In Europe injuries account for $7 \%$ of all deaths every year, with traffic injuries (16\%), poisonings (13\%) and falls (10\%) being the main causes of death related with unintentional injuries, and suicides (19\%) and homicides (7\%) the leading causes of intentional injuries (WHO, 2012).

In recent decades injury mortality rates have fallen in most European countries (EUROSTAT, 2012), however there are still differences between countries in mortality due to these causes. In concrete, people living in low and middle income countries are more likely to die from injuries than those living in high income countries. These differences have been observed for all specific causes of injuries, except for falls in women (Sethi, et al, 2006). In addition, individuals of less favourable socioeconomic positions present higher risks of dying due to the leading specific causes of death by injuries (Cubbin and Smith, 2002,Laflamme, et al, 2009).

In recent years there has been an increase in the number of studies of mortality inequalities in geographical areas, since area of residence has been recognised as a factor affecting health independently of individual determinants (Diez Roux, 2001). In the case of injury related mortality, some studies have found that areas with worse socioeconomic indicators present higher risks of dying, in particular for homicides (Leyland and Dundas, 2010,Krueger, et al, 2004) and drug overdose (Gotsens, et al, 2011a,Michelozzi, et al, 1999). In the case of suicides and traffic injuries the findings are inconclusive. Some studies have found associations, both positive (Gotsens, et al, 2011a,Burrows, et al, 2010,Esnaola, et al, 2006,Chang, et al, 2011,Middleton, et al, 2006) and negative (Middleton, et al, 2004,Page, et al, 2002) in the case of suicides, while others have found no association (Esnaola, et al, 2006, Middleton, et al, 2004). In the case of falls, few studies have analysed socioeconomic inequalities for this cause at area level, these studies have not found any association with socioeconomic deprivation of residence area (Gotsens, et al, 2011a). Finally, it is important to note that the socioeconomic inequalities in mortality due to injuries are more pronounced among men for the majority of causes (Gotsens, et al, 2011a). 
In Europe, socioeconomic inequalities in injury related mortality at small area level have hardly been analysed, and the majority of studies have focused on comparisons between countries. Focus to urban population was rarely given, while, on one side, the majority of Europe's population lives in cities (United Nations,), on the other it is in the urban areas where certain external causes, such as traffic injuries involving pedestrians, homicides, or substance abuse are more common (Vlahov and Galea, 2002). Thus, the objective of the present study was to analyse socioeconomic inequalities in mortality due to the leading injury related causes of death in small areas of 15 European cities by sex, at the beginning of the 21 st century.

\section{METHODS}

Design, unit of analysis and study population

This was a cross-sectional ecological study which forms part of the INEQ-CITIES project (https://www.ucl.ac.uk/ineqcities/). The units of analysis were the small areas of 15 European cities. The selected cities of the study are the ones participating in this project. These cities were located in a variety of regions of Europe: North: Helsinki (Finland) and Stockholm (Sweden); West: London (UK), Amsterdam and Rotterdam (the Netherlands), Zurich (Switzerland) and Brussels (Belgium); South: Turin (Italy), Madrid and Barcelona (Spain), and Lisbon (Portugal); Central east: Budapest (Hungry), Kosice and Bratislava (Slovakia), and Prague (Czechia). The study population consisted of the individuals residents in the 15 cities during a period around 2000-2008.

\section{Information sources}

The majority of cities had mortality data for the years 2000-2008 and socioeconomic indicators for 2001. Mortality data were obtained from the mortality registers of the cities or countries. Due to technical problems, georeferencing of place of residence could not be done for several deaths in 8 cities (percentage varying between $0.24 \%$ in Brussels to $2.75 \%$ ). The population data stratified by age (in five-year groups), sex and small area were obtained from census data or from the Register of Inhabitants for each city. Socioeconomic indicators were also obtained from census data in the majority of cities except in, 
Amsterdam and Rotterdam which were obtained from the Annual Labour Force Survey for the years 1996-2008 and Helsinki and Stockholm which were obtained from the Register for 2001.

\section{Mortality and socioeconomic deprivation index}

The present study has analysed all deaths due to injuries (International Classification of Diseases 9th edition -ICD9-: E800-E999, 304, 305(and the 4th digits of ICD9: .2,.3,.4,.5,.6,.7,.8), International Classification of Diseases 10th edition -ICD10-: V01-Y89, F11-F16,F19) and from five specific causes of death due to injuries: transport injuries (ICD9: E800-E848, ICD10: V01-V99), drug overdoses (ICD9: E850(.0,.9), E851-E855, E858(.8,.9), 304, 305(.2,.3,.4,.5,.6,.7,.8), ICD10: X41-X44, F11-F16, F19), falls (ICD9: E880-E888, ICD10: W00-W19), suicides (ICD9: E950-E959, ICD10: X60-X84) and homicides (ICD9: E960-E969, ICD10: X85-Y09).

We included as a covariate an index of socioeconomic deprivation available for each small area of each city. The socioeconomic indicators included in the index were: (a) Unemployment: percentage of people aged 16 years or over unemployed or actively seeking job in relation to the total economically active population; (b) Manual workers: percentage of people aged 16 or over, employed, who are manual workers, in relation to the total employed population aged 16 or over; (c) Low education in young people (16-25 years): percentage of 16-25 years old population with primary education or lower level in relation to the total population aged 16-25 years; (d) University qualifications in young people (25-34 years): percentage of 25-34 years old population with university education in relation to the total population aged 25-64 years; (e) Foreigners low income countries: percentage of foreigners from low income countries in relation to the total population. Although the INEQ-CITIES project collected information on other socioeconomic indicators, the socioeconomic indicators that were used to create this index were the most comparable indicators across the cities. The index of socioeconomic deprivation was constructed by the DP2 method. DP2 is an iterative procedure that weights partial indicators depending on their correlation with the global index. This construction overcomes several limitations of the standard Principal Component Analysis method, for instance, aggregating variables expressed in different units of measurement, arbitrary weights, the treatment of missing values and duplicate information. In addition, the DP2 method allows a joint analysis of the data from all the cities in order to obtain a single index of 
deprivation. Consequently, this deprivation index is comparable across all the cities studied (Pena Trapero, 1977,Salcedo, et al, 2012).

\section{Data analysis}

The mortality indicator used for the analysis is the Standardized Mortality Ratio (SMR). The SMR is dependent on population size since its variance is inversely proportional to the expected values, thus areas with low population tend to present estimates with a high variance. In order to smooth the SMR we used the hierarchical Bayesian model proposed by Besag, York and Mollié (BYM) (Besag, et al, 1991). This model takes two types of random effects into account, spatial and heterogeneous: the former takes account of the spatial structure of the data while the latter deals with non-structural (non-spatial) variability. Smoothed SMR (sSMR) were estimated for each cause of death, sex and city with the following model:

$$
\begin{aligned}
& \mathrm{O}_{\mathrm{i}} \sim \text { Poisson }\left(\mathrm{E}_{\mathrm{i}} \theta_{\mathrm{i}}\right) \\
& \log \left(\theta_{\mathrm{i}}\right)=\alpha+\mathrm{S}_{\mathrm{i}}+\mathrm{H}_{\mathrm{i}}
\end{aligned}
$$

(model 1)

where, for each area $\mathrm{i}, \mathrm{O}_{\mathrm{i}}$ is the number of observed cases, $\mathrm{E}_{\mathrm{i}}$ the expected cases, $\theta_{\mathrm{i}}$ the relative risk with respect to the European population, $\mathrm{S}_{\mathrm{i}}$ the spatial effect, and $\mathrm{H}_{\mathrm{i}}$ the heterogeneous effect. The expected cases in each small area were calculated by indirect standardization taking as reference the mortality rates of 25 countries of the European Union for the year 2004, by sex, age (in 5 year groups) and cause of death, these data having been provided by the World Health Organization (WHO 2011).

The geographical distribution of the SMR calculated through model 1 has been represented using maps of septiles. Moreover, the deprivation index has also been represented as septile maps. All maps were generated using the R statistical package (R Development Core Team, 2012).

In order to analyse the relationship between mortality and socioeconomic deprivation, we fitted an ecological regression model (model 2) which included the deprivation index $\left(\mathrm{X}_{\mathrm{i}}\right)$ as a covariate:

$$
\mathrm{O}_{\mathrm{i}} \sim \text { Poisson }\left(\mathrm{E}_{\mathrm{i}} \theta_{\mathrm{i}}\right)
$$




$$
\log \left(\theta_{\mathrm{i}}\right)=\alpha+\beta_{1} \mathrm{X}_{\mathrm{i}}+\mathrm{S}_{\mathrm{i}}+\mathrm{H}_{\mathrm{i}}
$$

(model 2)

where $\exp \left(\beta_{1}\right)$ denotes the relative risk $(\mathrm{RR})$ associated with the deprivation index.

In the two models (model 1 and model 2), an intrinsic conditional autoregressive prior distribution (ICAR)(Besag, et al, 1991) was assigned to the spatial effect, which assumes that the expected value of each area coincides with the mean of the spatial effect of the adjacent areas and has variance of $\sigma_{s}^{2}$, while the heterogeneous effect was represented using independent normal distributions with mean 0 and

variance $\sigma_{h}^{2}$. A half-normal distribution with mean 0 and precision 0.0001 was assigned to the standard deviations $\sigma_{s}$ and $\sigma_{h}$ (Gelman, 2006). A normal vague prior distribution was assigned to the parameters $\alpha$ and $\beta_{1}$.

Relative risk (RR) estimates were obtained based on their posterior means, along with the corresponding 95\% credible intervals $(95 \% \mathrm{CI})$. These distributions were obtained with the "Integrated nested Laplace approximation" (INLA) method, using the INLA library of the R statistical package, R.2.10.1 (Rue and Martino, 2009). This method provides reliable estimates of the posterior distributions avoiding the problems and computing time that would entail resorting to Monte Carlo methods.

The analyses were performed for each city stratifying by sex in order to control for possible interactions between socioeconomic deprivation and sex, due to the different impact of injury mortality in men and women (Laflamme, et al, 2009, Gotsens, et al, 2011a). Finally, for deaths due to homicides and drug overdose, modelling was not feasible for Stockholm, Turin, Madrid, Barcelona, Kosice and Prague due to the small numbers of deaths in respect to the number of areas in each city.

\section{RESULTS}

Table 1 presents the number of small areas, the total population and the distribution of the population by small area in each city. The number of small areas varies from 17 in Bratislava to 2666 in Turin. The 
median population per small area also varies by city. For example, the median population per area in Turin was 274 inhabitants while in Budapest it was 76,970 inhabitants. Both facts indicate that the size of the small areas with available data is different in each city. This table also includes a description of the deprivation index. The median value of deprivation index varies from 3.2 in Stockholm to 7.8 in Madrid and London. Higher scores in the deprivation index represented higher socioeconomic deprivation.

Table 2 presents the number of deaths by cause and sex in each city. In the majority of the cities, the number of deaths from all specific injury causes is higher in men, with the exception of falls. Among men, the most common cause of death is suicide in most cities except in Turin, where the most frequent cause are falls, and in Madrid, Lisbon and Kosice, where the most frequent cause of death are transport injuries. Among women, in most cities the most common cause of death are falls, except in Stockholm and Amsterdam, where the most frequent cause are suicides, and in Lisbon and Kosice, where the most frequent cause of death are transport injuries. In men, Helsinki and the cities of central eastern Europe have the highest mortality rates from all injuries. The cities of southern and central eastern Europe also have the highest mortality rates from transport injuries, while London and the southern cities show the lowest deaths rates from suicides. In women, the cities of southern and central eastern Europe, are characterized by the highest mortality rates from transport injuries, while Helsinki and western cities except London, show the highest mortality rates from homicides.

Figure 1 shows a selection of maps with different geographical patterns for mortality and deprivation in four cities of different parts of Europe. It shows that the spatial patterns for deprivation index and mortality due to drug overdose in Helsinki and London are similar, whereas the patterns for the deprivation index and mortality due to suicides in Lisbon are reversed. Finally, the pattern of mortality due to all injuries has no relationship with the deprivation index in Prague (maps for all causes and cities are found in: https://www.ucl.ac.uk/ineqcities/atlas).

Table 3 presents the association between the deprivation index and injury mortality in men. In general, the results show that in the cities of northern and western Europe, there is a positive association between the deprivation index and most causes of death, whereas no association is detected in the majority of central eastern European cities. Regarding all injury mortality there is an association significantly higher 
than 1 with the deprivation index in most cities. The highest $R R$ is obtained in Stockholm $(\mathrm{RR}=1.266$, 95\% CI: 1.220 to 1.313 ). In relation to specific causes of death, drug overdoses and homicides are the causes presenting the strongest significant positive associations with the deprivation index. In the case of drug overdoses, five cities show a significant positive association with the deprivation index; the two highest RRs are found in Stockholm with $\mathrm{RR}=1.541$ (95\% CI: 1.377 to 1.726$)$ and in Helsinki with $\mathrm{RR}=1.383$ (95\% CI: 1.181 to 1.616$)$. For homicides, seven cities present a significant positive association with deprivation index, the highest $\mathrm{RR}$ is found in Helsinki with RR=1.383 (95\% CI: 1.061 to 1.779 ). Moreover, there is a significant positive association between the deprivation index and suicide mortality in seven cities, the highest $\mathrm{RR}$ corresponding to Stockholm ( $\mathrm{RR}=1.224,95 \% \mathrm{CI}: 1.152$ to 1.302$)$. In the case of mortality due to transport injuries, there is a significant positive association in six cities, the highest $R R$ corresponding to Stockholm $(R R=1.175,95 \%$ CI: 1.070 to 1.286$)$. Finally, mortality due to falls only presents significant positive associations with the deprivation index in four cities, the highest $\mathrm{RR}$ are found in Lisbon $(\mathrm{RR}=1.190,95 \% \mathrm{CI}: 1.105$ to 1.280$)$.

Table 4 presents the association between the deprivation index and injury mortality in women. In general the RRs are smaller, and the associations are less often significant, than for men. The results show that in some cities of northern and western Europe there exists the most association between the deprivation index and causes of death, whereas no association is detected in the majority of southern and central eastern cities. Regarding all injury mortality there is an association significantly higher than 1 with the deprivation index in seven cities. The highest $R R$ is obtained in Stockholm $(R R=1.174,95 \%$ CI: 1.122 to 1.227). In relation to specific causes of death, drug overdoses and homicides are the causes presenting the strongest significant positive association with the deprivation index. Four cities present a significantly positive association with the deprivation index for either of these causes. The highest significant RRs are found in Helsinki with $\mathrm{RR}=1.328,95 \% \mathrm{CI}$ : 1.122 to 1.571 for drug overdose and $\mathrm{RR}=1.449,95 \% \mathrm{CI}$ : 1.098 to 1.887 for homicides. In relation to suicide, a significant positive association with deprivation index is observed in Stockholm $(\mathrm{RR}=1.183,95 \% \mathrm{CI}$ : 1.086 to 1.287$)$, while Zurich ( $\mathrm{RR}=0.836,95 \%$ CI: 0.782 to 0.892$)$ and Lisbon ( $\mathrm{RR}=0.904,95 \% \mathrm{CI}: 0.823$ to 0.990$)$ present negative associations. In the case of falls the only significantly positive association is in Rotterdam ( $\mathrm{RR}=1.088,95 \% \mathrm{CI}: 1.034$ to 1.142) and with regard to transport injuries no significant association with the deprivation index is found in any of the cities studied. 


\section{DISCUSSION}

Socioeconomic inequalities in injury related mortality can be observed in the majority of the cities studied. These inequalities are more pronounced in men. Specifically, in the cities of northern and western Europe, socioeconomic inequalities in injury mortality are found for most of the specific causes studied. These inequalities are not significant in the majority of the cities of southern Europe in women and in the majority of the central eastern Europe in both sexes. With regard to specific causes, drug overdose and homicide are the causes presenting the strongest associations with the deprivation index, in both sexes, in the majority of the cities.

The present study reveals, apart from the existence of socioeconomic inequalities in injury related deaths, the variations in magnitude of these inequalities between cities situated in different regions of Europe. Although we are not aware of previous studies analyzing socioeconomic inequalities in injury related mortality in small areas within cities, there are studies which have analysed differences in injury mortality between countries. These studies have found that low and medium income countries (which include Hungary, Slovakia, and Czechia) have higher risks of death due to all types of injuries, with the exception of falls among women, compared to high income countries (Sethi, et al, 2006). Other studies have analysed mortality inequalities, in terms of educational level, for certain specific causes of injury in various European countries. These studies have found association between injury mortality and low educational level (Borrell, et al, 2005,Mackenbach, et al, 2008,Leinsalu, et al, 2009).

The differences in magnitude of the socioeconomic inequalities found between cities may be due to various reasons. On the one hand, it is important to point out that the cities studied present different physical, political, social and cultural environments which may affect the causes and determinants of injuries. Thus, for example, in some central eastern countries of Europe, the strategic investments in departments of public health needed to form effective responses to epidemics of chronic disease and injury that occurred in these countries during the middle of the 1990s, was minimal (Zatonski and HEM project team, 2011). On the other hand, the results show that socioeconomic differences seem to be greater where the injury mortality rates are lower. In addition, the results also show no significant associations in most cities in central eastern Europe, and this may be due to the lack of statistical power 
due to the small number of geographic areas analysed in some cities in this region of Europe. Thus the absence of significant associations does not imply that the effect of deprivation on injury related mortality is negligible in these cities. In addition, the cities with small number of areas also have larger areas, and therefore are more homogeneous making the detection of inequalities difficult. In this sense, the variations in the deprivation index between city areas in central eastern Europe seem to be smaller than in other European cities. The deprivation index might be a better discriminator between areas in the cities of North, South and West of Europe than in the central east cities, and other contextual factors may be more relevant in the cities of this region.

Second, there may be differences between the cities in regard to coding of injuries in mortality registers. This fact could have consequences for the reliability of the data, since injuries may be under-reported in the mortality registries of some cities. Registration of these causes is a complex procedure which combines medical and legal aspects. Moreover, various authorities are involved in the procedures, which may vary between countries (Varnik, et al, 2010,Gotsens, et al, 2011b). For example, in the cases of injury death, in some countries, it is not obligatory to perform an autopsy and the legal authorities decide whether a forensic autopsy is necessary. This is the situation in the Netherlands, Belgium and Portugal. In contrast, in Hungary autopsies are performed in all cases of deaths due to injury. The low under-reporting of injuries in Hungarian mortality registers could explain why Budapest is the only city of central eastern Europe where socioeconomic inequalities have been detected for some causes. Another important aspect is the lack of communication between the person certifying the death and the legal authority in charge of the legal investigation. If this investigation produces a different decision about the cause of death, this information is not communicated to the certifier and the cause of death is not modified in the mortality statistics. This happens in the Netherlands and in Spain, for example (Varnik, et al, 2010,Gotsens, et al, 2011b).

In regard to the injury related mortality inequalities within a given city, our results agree with previous studies which have found that areas with worse socioeconomic indicators present higher all injuries mortality risk, and that the magnitudes of these inequalities are greater among men (Gotsens, et al, 2011a,Michelozzi, et al, 1999). Men, apart from being more exposed to suffering an injury, present more risky behaviours (driving fast, not using safety measures, higher consumption of alcohol and of drugs, 
etc.) than women. These behaviours increase their risk of suffering disease, injury or death (Courtenay, 2000). It could be that the expression of masculinity mentioned above (worse behaviours among men) is more pronounced among those of deprived areas, a fact that might explain why the RR are higher among men than among women.

With regard to unintentional injuries, we have found socioeconomic inequalities in mortality from transport injuries in some cities in men. This agrees with some studies that have found that areas with worse socioeconomic indicators presented higher mortality risk related to traffic injuries (Laflamme, et al, 2009,Gotsens, et al, 2011a,Michelozzi, et al, 1999). More deprived areas might have poorer built environment and more infrastructure problems which can explain these inequalities. However, some studies conducted in cities of southern Europe have not found these inequalities (Esnaola, et al, 2006). In addition, some studies have found associations between mortality due to traffic injuries and physical and socioeconomic characteristics of the area where the injury occurred, which might be different from the area of residence (Haynes, et al, 2005,Jones, et al, 2008). In the case of drug overdose, some studies conducted in cities of southern Europe have found that areas with greater socioeconomic deprivation present higher mortality risks (Gotsens, et al, 2011a,Michelozzi, et al, 1999,Esnaola, et al, 2006). For falls, there are very few studies which have analysed socioeconomic inequalities in mortality for this cause at ecological level, and these studies did not find socioeconomic inequalities (Gotsens, et al, 2011a). The studies on falls often focus on children or the elderly, which are the most vulnerable groups.

In relation to intentional injuries, some studies have found that areas with greater socioeconomic deprivation present higher suicide mortality risks (Burrows, et al, 2010,Esnaola, et al, 2006,Chang, et al, 2011,Middleton, et al, 2006) and this would agree with our findings among men in the majority of the cities. In women, we only found a positive association with the deprivation index in Stockholm. Moreover, in Zurich and Lisbon we found an inverse relationship with the deprivation index. This divergence in direction of the association agrees with the findings of some review papers (Cubbin and Smith, 2002,Rehkopf and Buka, 2006). In the case of homicides, some studies conducted in the United States (Cubbin, et al, 2000), Brazil (Viana, et al, 2011), Great Britain (Shaw, et al, 2005) and Scotland (Leyland and Dundas, 2010) have reported a positive association between homicides and area 
socioeconomic deprivation. However, it is important to note that few such studies have been conducted in European countries (Laflamme, et al, 2009).

\section{Limitations and strengths}

The main limitation of this study is the comparability of the data. In this regard there are considerable differences in numbers and sizes of the small areas in the different cities studied. This fact can have an influence in terms of low statistical power of the data to detect significant associations, especially in the cities of central eastern Europe. For this reason it is difficult to conclude on any substantial differences in patterns between central eastern cities and other cities. Moreover, although the deprivation index used in the study is comparable for all of the cities, it is important to note that for Amsterdam and Rotterdam the indicators used to elaborate the deprivation index are not based on a full population census. Finally, in some cities it was not possible to analyse all causes due to the small numbers of deaths observed in respect to the number of areas in each city.

The main strength of the study is that, to our knowledge, it is the first project to analyse inequalities in mortality due to all injuries, and to the leading injury related causes in 15 cities of different regions of Europe at small area level. In this sense, the processes occurring in urban areas are important factors to understand the economic, social, political and health transformations in a country. In addition, these cities have different socioeconomic contexts, something which provides a broad overview of the behaviour of these causes and lends consistency to the results found. Finally, studies of small areas are less susceptible to the ecological bias component created by heterogeneity within the exposure areas or other determining factors (Richardson, et al, 2004), and in addition permit detection of geographical patterns in mortality and deprivation which would not be evident with larger geographical areas.

\section{CONCLUSIONS}

This study confirms the existence of socioeconomic inequalities in injury related mortality, and highlights the differences in their magnitude between various cities from different regions of Europe, with differing socioeconomic context. Studies of this type may allow identification of geographical patterns and of areas with high mortality risk and poor socioeconomic indicators, which helps when developing interventions 
aimed at reducing such inequalities. Furthermore, knowing that a health problem has a pattern of inequality is a first step to ensure that interventions aiming to address the problem will take these differences into account. For this reason, the researchers of INEQ-CITIES project have disseminated the results (Camprubi, et al, 2013) and have produced an atlas of inequalities in mortality in European cities, which is freely available online (https://www.ucl.ac.uk/ineqcities/atlas). However, despite growing awareness of the existence of socioeconomic inequalities in injury related mortality, not all European countries have developed policies to reduce them. Progress in this field requires strong political will, commitments in the long term and inter-sectorial collaboration with priority of creating safe environments (safer roads, safer night environments, better housing, etc.) (Borrell, et al, 2013,Comision Para Reducir Las Desigualdades Sociales En Salud En Espana, 2012). Moreover, the experience and knowledge generated in the different European countries may be used to identify and promote codes of good practice although, to be effective, interventions and programmes must be adapted to the context of each city.

\section{ACKNOWLEDGEMENTS}

This article has been partially funded by the project INEQ-CITIES, "Socioeconomic inequalities in mortality: evidence and policies of cities of Europe"; project funded by the Executive Agency for Health and Consumers (Commission of the European Union), project nº2008 1213

Competing interests: The authors declare that they have no conflict of interest.

\section{REFERENCES}

Besag, J., York, J., Mollié A., 1991. Bayesian image restoration, with two applications in spatial statistics. Annals of the Institute of Statistical Mathematics 43(1), 1-59.

Borrell, C., Plasencia, A., Huisman, M., Costa, G., Kunst, A., Andersen, O., Bopp, M., Borgan, J.K., Deboosere, P., Glickman, M., Gadeyne, S., Minder, C., Regidor, E., Spadea, T., Valkonen, T., Mackenbach, J.P., 2005. Education level inequalities and transportation injury mortality in the middle aged and elderly in European settings. Injury prevention 11, 138-142. 
Borrell, C., Pons-Vigues, M., Morrison, J., Diez, E., 2013. Factors and processes influencing health inequalities in urban areas. Journal of epidemiology and community health 67, 389-391.

Burrows, S., Auger, N., Roy, M., Alix, C., 2010. Socio-economic inequalities in suicide attempts and suicide mortality in Quebec, Canada, 1990-2005. Public health 124, 78-85.

Camprubi, L., Diez, E., Morrison, J., Borrell, C., 2013. The Ineq-Cities research project on urban health inequalities: knowledge dissemination and transfer in Spain. Gaceta sanitaria / S.E.S.P.A.S..

Chang, S.S., Sterne, J.A., Wheeler, B.W., Lu, T.H., Lin, J.J., Gunnell, D., 2011. Geography of suicide in Taiwan: Spatial patterning and socioeconomic correlates. Health \& place 17, 641-650.

Comisión Para Reducir Las Desigualdades Sociales En Salud En España, 2012. A proposal of policies and interventions to reduce social inequalities in health in Spain. Gaceta Sanitaria 26, 182-189.

Courtenay, W.H., 2000. Constructions of masculinity and their influence on men's well-being: a theory of gender and health. Social science \& medicine (1982) 50, 1385-1401.

Cubbin, C., LeClere, F.B., Smith, G.S., 2000. Socioeconomic status and injury mortality: individual and neighbourhood determinants. Journal of epidemiology and community health 54, 517-524.

Cubbin, C., Smith, G.S., 2002. Socioeconomic inequalities in injury: critical issues in design and analysis. Annual Review of Public Health 23, 349-375.

Diez Roux, A.V., 2001. Investigating neighborhood and area effects on health. American Journal of Public Health 91, 1783-1789.

Esnaola, S., Aldasoro, E., Ruiz, R., Audicana, C., Perez, Y., Calvo, M., 2006. [Socioeconomic inequalities in mortality in the Basque Country [Spain]]. Gaceta sanitaria 20, 16-24.

EUROSTAT, 2012. Causes of death. http://epp.eurostat.ec.europa.eu/portal/page/portal/health/public_health/data_public health/database. Accessed 4 Dec 2012. 
Gelman, A., 2006. Prior distributions for variance parameters in hierarchical models. Bayesian Analysis $3,515-533$.

Gotsens, M., Mari-Dell'Olmo, M., Martinez-Beneito, M.A., Perez, K., Pasarin, M.I., Daponte, A., Puigpinos-Riera, R., Rodriguez-Sanz, M., Audicana, C., Nolasco, A., Gandarillas, A., Serral, G., Dominguez-Berjon, F., Martos, C., Borrell, C., 2011a. Socio-economic inequalities in mortality due to injuries in small areas of ten cities in Spain (MEDEA Project). Accident; Analysis and Prevention 43, 1802-1810.

Gotsens, M., Mari-Dell'Olmo, M., Rodriguez-Sanz, M., Martos, D., Espelt, A., Perez, G., Perez, K., Teresa Brugal, M., Barberia Marcalain, E., Borrell, C., 2011b. Validation of the underlying cause of death in medicolegal deaths. Revista Española de Salud Pública 85, 163-174.

Haynes, R., Jones, A., Harvey, I., Jewell, T., Lea, D., 2005. Geographical distribution of road traffic deaths in England and Wales: place of accident compared with place of residence. J.Public Health (Oxf) 27, 107-111.

Jones, A.P., Haynes, R., Kennedy, V., Harvey, I.M., Jewell, T., Lea, D., 2008. Geographical variations in mortality and morbidity from road traffic accidents in England and Wales. Health \& place 14, 519-535.

Krueger, P.M., Bond Huie, S.A., Rogers, R.G., Hummer, R.A., 2004. Neighbourhoods and homicide mortality: an analysis of race/ethnic differences. Journal of epidemiology and community health 58, 223230.

Laflamme, L., Burrows, S., Hasselberg, M., 2009. Socioeconomic diferences in injury risks. A review of findings and a disucussion of potential countermeasures. WHO Regional Office for Europe.

Leinsalu, M., Stirbu, I., Vagero, D., Kalediene, R., Kovacs, K., Wojtyniak, B., Wroblewska, W., Mackenbach, J.P., Kunst, A.E., 2009. Educational inequalities in mortality in four Eastern European countries: divergence in trends during the post-communist transition from 1990 to 2000. International journal of epidemiology 38, 512-525.

Leyland, A.H., Dundas, R., 2010. The social patterning of deaths due to assault in Scotland, 1980-2005: population-based study. Journal of epidemiology and community health 64, 432-439. 
Mackenbach, J.P., Stirbu, I., Roskam, A.J., Schaap, M.M., Menvielle, G., Leinsalu, M., Kunst, A.E., European Union Working Group on Socioeconomic Inequalities in Health, 2008. Socioeconomic inequalities in health in 22 European countries. The New England journal of medicine 358, 2468-2481.

Michelozzi, P., Perucci, C.A., Forastiere, F., Fusco, D., Ancona, C., Dell'Orco, V., 1999. Inequality in health: socioeconomic differentials in mortality in Rome, 1990-95. Journal of epidemiology and community health 53, 687-693.

Middleton, N., Sterne, J.A., Gunnell, D., 2006. The geography of despair among 15-44-year-old men in England and Wales: putting suicide on the map. Journal of epidemiology and community health 60, 10401047.

Middleton, N., Whitley, E., Frankel, S., Dorling, D., Sterne, J., Gunnell, D., 2004. Suicide risk in small areas in England and Wales, 1991-1993. Social psychiatry and psychiatric epidemiology 39, 45-52.

Page, A., Morrell, S., Taylor, R., 2002. Suicide differentials in Australian males and females by various measures of socio-economic status, 1994-98. Australian and New Zealand Journal of Public Health 26, 318-324.

Pena Trapero, J.B., 1977. Problemas De La Medición Del Bienestar y Conceptos Afines:(Una Aplicación Al Caso Español).

R Development Core Team, 2012. R: A Language and Environment for Statistical Computing. Vienna, Austria: R Foundation for Statistical Computing, ISBN 3-900051-07-0, 2012 [Available at: http://www.R-project.org].

Richardson, S., Thomson, A., Best, N., Elliott, P., 2004. Interpreting posterior relative risk estimates in disease-mapping studies. Environmental health perspectives 112, 1016-1025.

Rue, H., Martino, S., 2009. INLA: Functions which allow to perform a full Bayesian analysis of structured additive models using Integrated Nested Laplace Approximaxion. R package version 0.0. .

Salcedo, N., Saez, M., Bragulat, B., Saurina, C., 2012. Does the effect of gender modify the relationship between deprivation and mortality? BMC public health 12, 574 . 
Sethi, D., Racioppi, F., Baumgarten, I., P, V., 2006. Injuries and violence in Europe: Why they matter and what can be done. World Health Organization.

Shaw, M., Tunstall, H., Dorling, D., 2005. Increasing inequalities in risk of murder in Britain: trends in the demographic and spatial distribution of murder, 1981-2000. Health \& place 11, 45-54.

United Nations 2011. World Urbanization Prospects: 2011 Revision. http://esa.un.org/unup/CD-

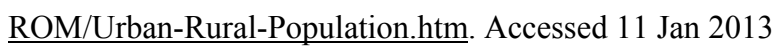

Varnik, P., Sisask, M., Varnik, A., Laido, Z., Meise, U., Ibelshauser, A., Van Audenhove, C., Reynders, A., Kocalevent, R.D., Kopp, M., Dosa, A., Arensman, E., Coffey, C., van der Feltz-Cornelis, C.M., Gusmao, R., Hegerl, U., 2010. Suicide registration in eight European countries: A qualitative analysis of procedures and practices. Forensic science international 202, 86-92.

Viana, L.A., Costa Mda, C., Paim, J.S., Vieira-da-Silva, L.M., 2011. Social inequalities and the rise in violent deaths in Salvador, Bahia State, Brazil: 2000-2006. Cadernos de saude publica / Ministerio da Saude, Fundacao Oswaldo Cruz, Escola Nacional de Saude Publica 27 Suppl 2, S298-308.

Vlahov, D., Galea, S., 2002. Urbanization, urbanicity, and health. Journal of urban health : bulletin of the New York Academy of Medicine 79, S1-S12.

WHO, 2012. Global burden of disease: disease and injury regional mortality estimates for 2008. Geneva, World Health Organization.

http://www.who.int/healthinfo/global_burden_disease/estimates_regional/en/index.html. Accessed $17 \mathrm{Jul}$ 2012.

WHO, 2011. European detailed mortality database [online database]. http://data.euro.who.int/dmdb/. Updated July 2010 version. Accessed 19 Dec 2011.

Zatonski, W.A., HEM project team, 2011. Epidemiological analysis of health situation development in Europe and its causes until 1990. Annals of Agricultural and Environmental Medicine : AAEM 18, 194202. 
Fig. 1 Distribution of deprivation index and smoothed Standardised Mortality Ratio (sSMR) for drug overdose in Helsinki and London, suicide in Lisbon and all injuries in Prague. White tones represent areas with mortality deficit or lower deprivation index, while those with excess mortality or higher deprivation index are represented with black tones. Men and women

Table 1 Number of small areas, population year, total population and distribution of population and the deprivation index in each city.

\begin{tabular}{|c|c|c|c|c|c|c|c|c|c|c|}
\hline \multirow{2}{*}{$\begin{array}{l}\text { Europe } \\
\text { an } \\
\text { Region }\end{array}$} & \multirow[b]{2}{*}{ City/Region } & \multirow{2}{*}{$\begin{array}{l}\text { Number of } \\
\text { areas }\end{array}$} & \multicolumn{5}{|c|}{ Total population } & \multicolumn{3}{|c|}{ Deprivation index } \\
\hline & & & $\begin{array}{c}\text { Yea } \\
\text { r }\end{array}$ & Total & $\mathbf{P}_{25}$ & $\mathbf{P}_{50}$ & $\mathbf{P}_{75}$ & $\mathbf{P}_{25}$ & $\mathbf{P}_{50}$ & $\mathbf{P}_{75}$ \\
\hline \multirow[t]{2}{*}{ North } & Helsinki & 94 & 200 & 542,701 & 2962 & 4962 & 7965 & 3. & 4. & 5. \\
\hline & Stockholm & 117 & 200 & $1,864,3$ & 487 & 1202 & 2193 & 2. & 3. & $\hat{4}$ \\
\hline \multirow[t]{5}{*}{ West } & London & 633 & 200 & $7,172,0$ & 10,07 & 11,33 & 12,76 & 6. & 7. & 9. \\
\hline & Amsterdam & 94 & 200 & $738,32 \hat{2}$ & $351 \hat{8}$ & $758 \hat{2}$ & $11,5 \hat{1}$ & $\hat{4}$ & $\hat{6}$ & 8. \\
\hline & Rotterdam & 88 & 200 & 600,022 & 867 & 6595 & $10,5 \hat{4}$ & $\hat{4}$ & 6. & $\hat{9}$ \\
\hline & Zurich & 212 & 200 & 364,977 & 959 & 1618 & 2288 & $\hat{4 .}$ & $\overline{6}$. & $\hat{7}$ \\
\hline & Brussels Region & 118 & 200 & 970,037 & 5767 & 7779 & 10,62 & 5. & $\hat{7}$ & 9. \\
\hline \multirow[t]{4}{*}{ South } & Turin & 266 & 200 & 892,157 & 184 & 274 & 413 & 5. & 6. & 7. \\
\hline & Madrid & 235 & 200 & $3,149,6$ & 996 & 1239 & 1524 & $\hat{5 .}$ & 7. & $\hat{9 .}$ \\
\hline & Barcelona & $14 \hat{9}$ & $2 \tilde{00}$ & $1,588, \overline{4}$ & 788 & 974 & 1225 & 5 & $\hat{7}$ & 8. \\
\hline & Lisbon & 207 & 200 & $2,66 \hat{1, \hat{8}}$ & 4123 & 9738 & 17,62 & 4. & $\hat{5 .}$ & $\hat{6}$ \\
\hline \multirow[t]{4}{*}{ Centra } & Budapest & 23 & 200 & $1,705,3$ & 58,39 & 76,97 & 91,10 & 5. & 6. & 7. \\
\hline & Košice & 22 & 200 & 235,241 & $123 \hat{8}$ & $337 \hat{3}$ & $22,7 \hat{0}$ & 5. & 6 & $\hat{7 .}$ \\
\hline & Bratislava & 17 & 200 & 425,156 & 2354 & 18,72 & $34,5 \hat{9}$ & $\overline{3}$. & $\overline{4}$ & $\overline{4}$. \\
\hline & Prague & 57 & 200 & $1,170,5$ & 1768 & $319 \hat{7}$ & $27,2 \hat{1}$ & $\hat{4}$ & $\tilde{4}$ & $\hat{4}$ \\
\hline
\end{tabular}

$\mathrm{P}_{25}=$ percentile 25

$\mathrm{P}_{50}=$ percentile 50 (median)

$\mathrm{P}_{75}=$ percentile 75 
Table 2 Number of deaths (n) and crude mortality rate (MR) per 100,000 inhabitants by cause of death in men and women for each city.

\begin{tabular}{|c|c|c|c|c|c|c|c|c|c|c|c|c|c|c|}
\hline \multirow{2}{*}{$\begin{array}{l}\begin{array}{l}\text { Eur } \\
\text { ope }\end{array} \\
\text { Men }\end{array}$} & \multirow[t]{2}{*}{$\begin{array}{l}\text { City/Regio } \\
\text { n }\end{array}$} & \multirow[t]{2}{*}{$\begin{array}{c}\text { Peri } \\
\text { od }\end{array}$} & \multicolumn{2}{|c|}{$\begin{array}{c}\text { Transport } \\
\text { injury }\end{array}$} & \multicolumn{2}{|c|}{$\begin{array}{c}\text { Drug } \\
\text { overdose }\end{array}$} & \multicolumn{2}{|c|}{ Falls } & \multicolumn{2}{|c|}{ Suicide } & \multicolumn{2}{|c|}{$\begin{array}{c}\text { Homici } \\
\text { de }\end{array}$} & \multicolumn{2}{|c|}{$\begin{array}{c}\text { All } \\
\text { injuries }\end{array}$} \\
\hline & & & $\mathbf{n}$ & MR & $\mathbf{n}$ & $\mathbf{M}$ & $\mathbf{n}$ & M & $\mathbf{n}$ & $\mathbf{M}$ & $\mathbf{n}$ & $\mathbf{M}$ & $\mathbf{n}$ & MR \\
\hline \multirow[t]{2}{*}{ Nor } & Helsinki & 2000 & 20 & 8.1 & 2 & 10 & 6 & 25 & 7 & 30 & 7 & 2. & 26 & 10 \\
\hline & Stockholm & 2000 & 49 & 6.7 & 3 & 4. & 5 & 7. & 1 & 15 & 1 & 1. & 44 & 60. \\
\hline \multirow[t]{5}{*}{ We } & London & 2000 & 19 & 6.2 & 1 & 5. & 1 & 4. & 2 & 7. & 2 & 0. & 12 & 39. \\
\hline & Amsterdam & 1996 & 27 & 5.8 & 1 & 2. & 3 & 7. & 8 & 18 & 2 & 4. & 23 & 49. \\
\hline & Rotterdam & 1996 & 27 & 7.2 & 1 & 2. & 2 & 5. & 5 & 15 & 1 & 4. & 17 & 46. \\
\hline & Zurich & 2000 & 86 & 5.3 & 1 & 9. & 3 & 19 & 4 & 29 & 2 & 1. & 11 & 72. \\
\hline & Brussels & 2001 & 89 & 4.7 & 5 & 2. & 1 & 7. & 3 & 16 & 5 & 2. & 90 & 47. \\
\hline \multirow[t]{4}{*}{ Sou } & Turin & 1996 & 53 & 14. & 1 & 4. & 5 & 14 & 4 & 10 & 4 & 1. & 20 & 53. \\
\hline & Madrid & 2000 & 11 & 9.7 & 1 & 1. & 4 & 3. & 7 & 6. & 2 & 2. & 43 & 38. \\
\hline & Barcelona & 2000 & 58 & 8.7 & 3 & 5. & 4 & 6. & 7 & 10 & 8 & 1. & 34 & 51. \\
\hline & Lisbon & 1995 & 44 & 25. & 3 & 1. & 9 & 5. & 2 & 13 & 5 & 3. & 12 , & 69. \\
\hline \multirow[t]{4}{*}{ Cen } & Budapest & 2001 & 97 & 15. & 1 & 1. & 1 & 28 & 1 & 29 & 1 & 2. & 57 & 92. \\
\hline & Košice & 2000 & 22 & 21. & 2 & 0. & 1 & 11 & 1 & 18 & 2 & 2. & 93 & 91. \\
\hline & Bratislava & 2000 & 32 & 17. & 5 & 2. & 2 & 13 & 3 & 20 & 8 & 4. & 15 & 85. \\
\hline & Prague & 2003 & 33 & 11. & 2 & 0. & 4 & 14 & 6 & 21 & 4 & 1. & 21 & 77. \\
\hline \multicolumn{15}{|l|}{ Wo } \\
\hline \multirow[t]{2}{*}{$\mathrm{N}$} & Helsinki & 2000 & 77 & 2.6 & 1 & 4. & 5 & 20 & 3 & 13 & 4 & 1. & 15 & 53. \\
\hline & Stockholm & 2000 & 15 & 2.0 & 8 & 1. & 4 & 6. & 6 & 8. & 5 & 0. & 28 & 36. \\
\hline \multirow[t]{5}{*}{ W } & London & 2000 & 68 & 2.0 & 4 & 1. & 1 & 3. & 9 & 2. & 9 & 0. & 63 & 19. \\
\hline & Amsterdam & 1996 & 12 & 2.6 & 5 & 1. & 4 & 8. & 4 & 8. & 8 & 1. & 17 & 36. \\
\hline & Rotterdam & 1996 & 11 & 2.8 & 2 & 0. & 2 & 6. & 2 & 5. & 5 & 1. & 13 & 33. \\
\hline & Zurich & 2000 & 48 & 2.8 & 7 & 4. & 4 & 27 & 3 & 20 & 2 & 1. & 10 & 62. \\
\hline & Brussels & 2001 & 40 & 1.9 & 1 & 0. & 1 & 9. & 1 & 9. & 3 & 1. & 82 & 40. \\
\hline \multirow[t]{4}{*}{$\mathrm{S}$} & Turin & 1996 & 18 & 4.4 & 3 & 0 . & 9 & 21 & 1 & 4. & 3 & 0. & 16 & 38. \\
\hline & Madrid & 2000 & 42 & 3.3 & 4 & 0. & 5 & 4. & 3 & 2. & 9 & 0. & 25 & 19. \\
\hline & Barcelona & 2000 & 26 & 3.4 & 9 & 1. & 5 & 7. & 3 & 4. & 4 & 0. & 26 & 35. \\
\hline & Lisbon & 1995 & 15 & 8.0 & 4 & 0. & 7 & 4. & 8 & 4. & 1 & 1. & 54 & 28. \\
\hline \multirow[t]{4}{*}{ Cen } & Budapest & 2001 & 48 & 6.4 & 3 & 0. & 2 & 35 & 1 & 13 & 9 & 1. & 49 & 66. \\
\hline & Košice & 2000 & 81 & 7.3 & 1 & 0. & 4 & 4. & 5 & 4. & 9 & 0. & 31 & 28. \\
\hline & Bratislava & 2000 & 13 & 6.4 & 1 & 0. & 1 & 6. & 6 & 3. & 2 & 1. & 55 & 26. \\
\hline & Prague & 2003 & 15 & 5.0 & 12 & 0. & 62 & 20 & 21 & 6. & 2 & 0. & 14 & 47. \\
\hline
\end{tabular}


Table 3 Association between mortality and the deprivation index. Men

\begin{tabular}{|c|c|c|c|c|c|c|c|c|c|}
\hline \multirow[b]{2}{*}{ European Region } & \multirow[b]{2}{*}{ City/Region } & \multicolumn{2}{|c|}{ Transport Injury } & \multicolumn{2}{|c|}{ Drug overdose } & \multicolumn{2}{|r|}{ Falls } & \multicolumn{2}{|r|}{ Suicide } \\
\hline & & $\mathbf{R R}$ & $95 \%$ CI & $\mathbf{R R}$ & $95 \% \mathrm{CI}$ & $\mathbf{R R}$ & $95 \% \mathrm{CI}$ & $\mathbf{R R}$ & $95 \%$ CI \\
\hline \multirow[t]{2}{*}{ North } & Helsinki & 1.013 & $(0.890-1.148)$ & 1.383 & $(1.181-1.616)$ & 1.121 & $(1.034-1.210)$ & 1.164 & $(1.077-1.258)$ \\
\hline & Stockholm $^{\mathrm{a}}$ & 1.175 & $(1.070-1.286)$ & 1.541 & $(1.377-1.726)$ & 1.087 & $(0.998-1.183)$ & 1.224 & $(1.152-1.302)$ \\
\hline \multirow[t]{5}{*}{ West } & London & 1.045 & $(1.019-1.072)$ & 1.061 & $(1.021-1.103)$ & 1.021 & $(0.985-1.057)$ & 1.040 & $(1.015-1.067)$ \\
\hline & Amsterdam & 1.045 & $(1.004-1.088)$ & 1.057 & $(0.968-1.155)$ & 0.969 & $(0.929-1.010)$ & 1.024 & $(0.987-1.064)$ \\
\hline & Rotterdam & 1.045 & $(1.002-1.091)$ & 1.223 & $(1.122-1.339)$ & 1.067 & $(1.005-1.128)$ & 1.063 & $(1.029-1.098)$ \\
\hline & Zurich & 1.090 & $(0.968-1.219)$ & 1.116 & $(0.988-1.245)$ & 0.971 & $(0.903-1.041)$ & 1.014 & $(0.957-1.072)$ \\
\hline & Brussels Region & 1.061 & $(0.995-1.128)$ & 1.069 & $(0.983-1.158)$ & 1.035 & $(0.983-1.087)$ & 0.984 & $(0.942-1.025)$ \\
\hline \multirow[t]{4}{*}{ South } & Turin $^{\mathrm{a}}$ & 1.032 & $(0.991-1.074)$ & & & 1.041 & $(0.997-1.086)$ & 1.006 & $(0.958-1.053)$ \\
\hline & Madrid $^{\mathrm{a}}$ & 1.052 & $(1.025-1.079)$ & & & 1.015 & $(0.971-1.060)$ & 1.042 & $(1.007-1.078)$ \\
\hline & Barcelona $^{\mathrm{a}}$ & 1.028 & $(0.983-1.075)$ & 1.190 & $(1.122-1.260)$ & 1.040 & $(0.992-1.088)$ & 1.066 & $(1.031-1.102)$ \\
\hline & Lisbon Metropolitan Area & 1.072 & $(1.017-1.130)$ & 1.095 & $(0.960-1.247)$ & 1.190 & $(1.105-1.280)$ & 1.052 & $(0.984-1.123)$ \\
\hline \multirow[t]{4}{*}{ Central east } & Budapest & 1.024 & $(0.949-1.099)$ & 1.174 & $(0.824-1.661)$ & 1.132 & $(1.040-1.234)$ & 1.090 & $(1.029-1.158)$ \\
\hline & Košice $^{a}$ & 0.985 & $(0.894-1.067)$ & & & 1.021 & $(0.876-1.148)$ & 0.972 & $(0.852-1.077)$ \\
\hline & Bratislava & 1.040 & $(0.751-1.421)$ & 0.662 & $(0.281-1.198)$ & 1.156 & $(0.850-1.514)$ & 1.120 & $(0.835-1.472)$ \\
\hline & Prague $^{\mathrm{a}}$ & 0.925 & $(0.352-2.079)$ & & & 0.668 & $(0.271-1.368)$ & 1.222 & $(0.650-2.133)$ \\
\hline
\end{tabular}

RR: relative risk

$95 \%$ CI: credible interval at $95 \%$

${ }^{a}$ Due to the small numbers of deaths in respect to the number of areas in each city some causes have not been analysed

Table 4 Association between mortality and the deprivation index. Women

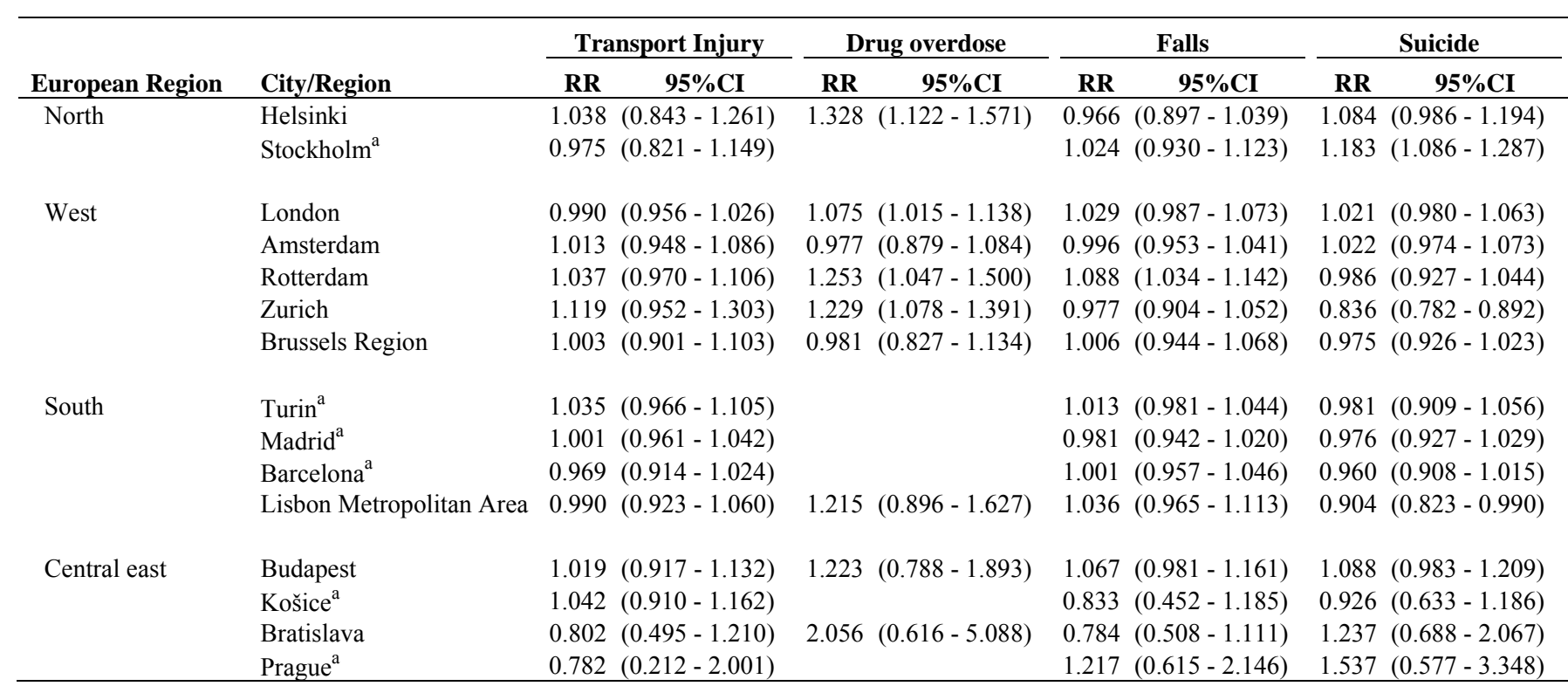

RR: relative risk

95\% CI: credible interval at $95 \%$

${ }^{a}$ Due to the small numbers of deaths in respect to the number of areas in each city some causes have not been analysed 


\section{Highlights:}

- Socioeconomic inequalities exist in injury mortality at small area level in most European cities.

- There are differences in the magnitude of these inequalities.

- Intersectorial collaboration is necessary to create safe environments. 
HELSINKI
Deprivation index

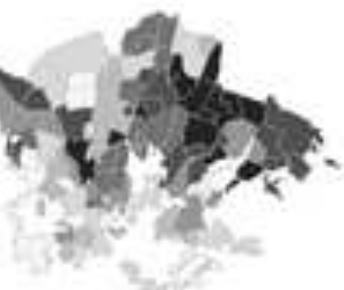

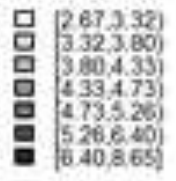

Drug overdose, men
LONDON

Deprivation index
LISBON

Deprivation index
PRAGUE

Deprivation index

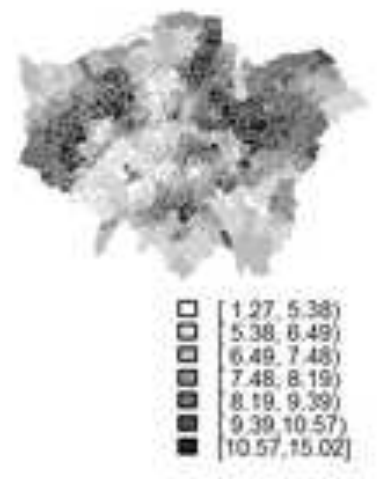

Drug overdose, men

Drug overdose, women

Drug overdose, women

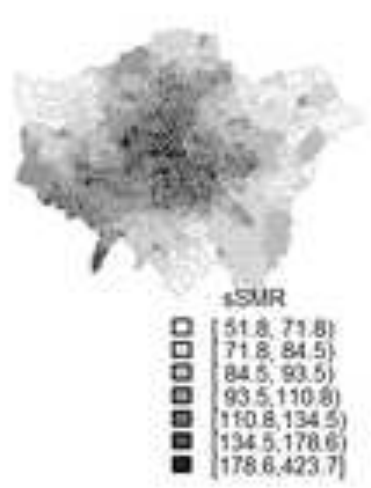

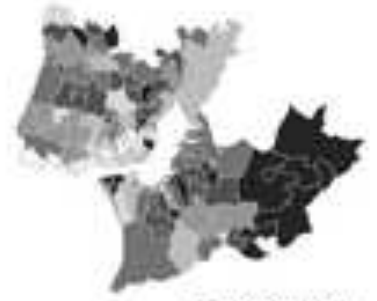

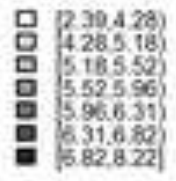

Suicide, men
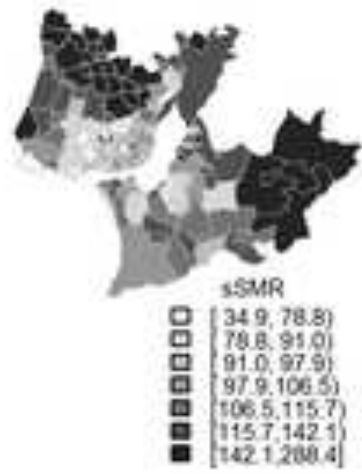

Suicide, women
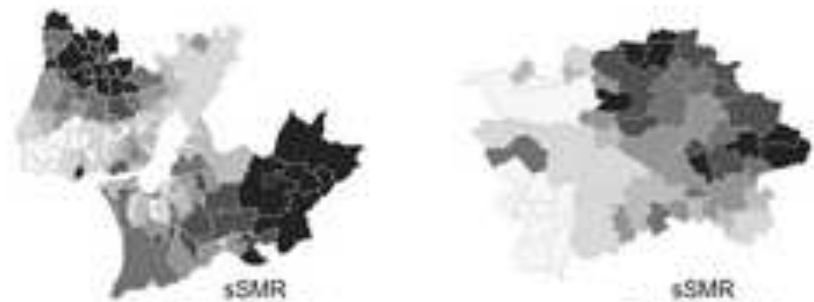

SSMR

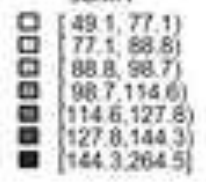

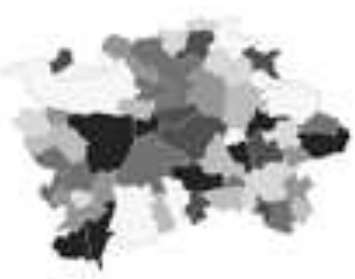

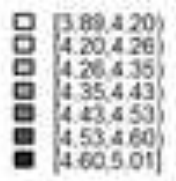

All injuries, men
All injuries, women

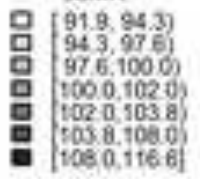

